\title{
A Cognophonetic Study of H-Epenthesis by Educated Yoruba-English Bilinguals
}

\author{
Mercy A. Bankole \\ Department of English \\ College of Education, Ikere-Ekiti \\ Ekiti state, Nigeria \\ Bunmi O. Esan \\ Department of English \\ University of Ibadan, Ibadan \\ Oyo State \\ Nigeria
}

\begin{abstract}
H-epenthesis in h-less words is reportedly a common characteristic of Yoruba-English bilinguals. This study investigated the possible cognitive motivation for h-epenthesis in Educated Yoruba-English speakers, with a view to identifying the constraint that is responsible for the realisation. Optimality Theory was employed as the theoretical basis. Thirty Educated Yoruba English speakers participated in the study by reading a text which contained several grammatical and content words that are peak-initiated. This was used alongside structured questionnaires. Recorded data were analysed perceptually and phonologically. Several words which would be meaningless to native speakers were derived. Where meaningful wordswere derived, the meaning of the new words altered the meaning of the entire sentences. H-epenthesis results from a high-ranking constraint, ONSET [h], which requires that syllables begin with the specified consonant $-h$. This constraint, which accounts for unconscious insertion of $[h]$ by the participants, ranks higher than DEP.Newly derived words were unfaithful to native speakers' input. This may contribute to communication failure between native speaker and Educated Yoruba English speakers.
\end{abstract}

Keywords: H-epenthesis, cognophonetics, Educated Yoruba-English speakers, constraints ranking, ONSET [h]

\section{Introduction}

The study of Nigerian English phonology has been extended to the regional level such as Hausa-English, Igbo-English and Yoruba-English by different scholars, which include Bamgbose (1995), Akinjobi (2004), Igboanusi (2006), Olaniyi (2011) and Utulu (2014). This is to corroborate and support Bamgbose's proposal in Akinjobi (2004: 558) that the concentration of the scholars should be on the task of specifying, describing and analyzing the forms of English usage in Nigeria rather than bothering themselves with the existence of Nigerian English or otherwise.

Awonusi (2004: 190) also opines that, while RP as a standard remains largely monolithic and accent remains a model, local standards should be developed, described and recognised as belonging to the community of world Englishes as long as intelligibility is not seriously impaired. This, therefore, calls for the need to approach Nigerian English from 'local' perspective, even at this time 'when the variety 'Nigerian English' increasingly attracts the attention of the international and growing community world-wide' (Jowitt, 2014: 63).

Yoruba-English, being a sub-variety of Nigeria English, has gained the attention of various scholars of various fields of interest, thereby giving rise to itsdescription. A few of such areTiffen (1974), Atoye (1980), Odumuh (1987), Olaoye (1989),Akindele \& Adegbite (1999),Igboanusi (2006), Robbin (2010), Robbin (2011),Akinkurolere \& Adewumi (2013), and Ogundepo (2015). Attempt has been made to distinguish between the variety of English spoken by the educated Yoruba and the uneducated. Thus, a sub-variety called Educated Yoruba English (EYE)has emerged in the literature, and this is not unconnected with the inclusion of education as an indispensable variable for the classification of English in Nigeria (Banjo, 1971;Adesanoye, 1973). Adesanoye (1973) bases his classification on proximity from British English. To him, there is a very close relationship between performance and educational attainment.

\section{The phonology of Yoruba English}

Some descriptions of the phonology of Yoruba English have concentrated on features peculiar only to some people or a region. 
Thus, a misrepresentation of Yoruba Englishhas been projected. Such is the claim that the voiceless labiodental fricative /f/ is substituted for voiced labiodental fricative /v/ by the Yoruba, whereas this is peculiar to some people from Ibadan. An appreciable number of people from Ibadan, mostespecially the educated ones, have tried to overcome the problem of substitution between the two sounds. Thus, the description of the substitution process between / $/$ and /f/ as a phonological marker of Yoruba languageis not justified. Moreover, Yoruba has the voiceless plosive ' $p$ ' in its orthography but not in its sound inventory. Instead, it has a diagraph $/ \mathrm{kp} /$. However, this does not suggest that the Yoruba cannot realise the phoneme correctly as claimed by Ekpe (2010) because Ufomata (2004) opines that voiceless bilabial plosive $/ \mathrm{p} /$ has been introduced into Yoruba. The pronunciation of $/ \mathrm{kp} /$ is only preserved in dialects and it characterises the speech of some uneducated speakers. The fact is that, it is hardly transferred into English.A cursory look at table 1 below justifies the assertion that the claim that $/ \mathrm{kp} /$ is not realised by the Yoruba is a misguided representation.

\begin{tabular}{|l|l|l|}
\hline SBE & EYE & BYV \\
\hline /pi:pl/ & /pi:pu/ & $/ \mathrm{kpi}: \mathrm{kpu} /$ \\
\hline /kıp/ & /kop/ & $/ \mathrm{kspu} /$ \\
\hline /perpo/ & /peipa/ & $/ \mathrm{kpeikpa/}$ \\
\hline /perl/ & /peil/ & $/ \mathrm{kpeili} /$ \\
\hline /pækıt/ & /paket/ & $/ \mathrm{kpaketi} /$ \\
\hline
\end{tabular}

Key:

SBE: Standard British English

EYE: Educated Yoruba English

BYV: Basilectal Yoruba Variant

All the examples shown in table 1 above are some words with voiceless bilabial plosive /p/ preceded or followed by different types of vowels in different distributions ofword position. Hardly will any Educated Yoruba English speaker realise the words as those termed BYV, except those whose accents are still influenced by their dialects.Thus, in order to give proper description of the phonology of Yoruba English, the phonological markers of the Educated Yoruba English speaker is taken as the standard, and this has gained attention of scholars like Akinjobi (2004, 2005, 2006, 2007, 2009a, 2009b), andOladipupo (2014).

For instance, English syllabic consonants such as /ḷ, ṇ/ serve as peaks in lieu of vowels in some words. Such are found in unstressed syllables word-finally. Rather than realising these syllabic consonants, Educated Yoruba English speakers have vowels inserted between the preceding consonants and the syllabic consonants (Akinjobi, 2009a). In such cases, the inserted vowels are usually quantitative and strong. The word bacon has its last syllable mostly produced as [kon], [kun] and [kən]. However, an insignificant $1 \%$ of the subjects realised it appropriately as [kn]. The last syllabic of sizzle is predominantly pronounced as [zul] by 78\%; [sul] is also realised but by few respondents (9\%). This shows that the /z/, which is absent in Yoruba, does not constitute problem for Educated Yoruba English speakers except for those speakers with special idiosyncratic feature.The syllabic is correctly realised by $13 \%$ of the respondents and this is considered negligible. The -tal of hospital, a word commonly used by Nigerians than the previous ones, is pronounced as [-tul], [-tal], [-təl] and [-d!̣]. It is insignificantly pronounced as [-tl]. Other tested words that receive an equal in respect of insertion are student, passion, happen, television, wrestle, muddle, peasant, little, madden, principal, principle, panel, petal,ribbon,bottle andtotal. Another process noticed for the repair of syllabic consonants is substitution of vowels for syllabic consonants. This occurred insignificantly in pebble, which is realised as [pebu].All the inserted vowels are found quantitative, a feature of all Yoruba vowels. This must have been transferred into English by the subjects.

In another study, Akinjobi (2009b) examines the realisation of weak forms of English grammatical words by Educated Yoruba English speakers. The results show that determiners, conjunctions, pronouns and auxiliary verbs are rarely realised in their weak forms by the subjects. /ə/, which mostly occurs in the weak forms of those words, is replaced with strong vowels like [o, a, u, i, 3], leaving significant rhythmic impact on the English spoken by Educated Yoruba bilinguals.

In connected speech, each word is not distinctly pronounced by native speakers; words are joined together (Oladipupo, 2014; Oladipupo \& Akinjobi, 2015). When this happen, some segments are influenced by others; some are deleted, assimilated or reduced. Liaison is one of the processes by which this becomes actualised. The findings of Oladipupo (2014) reveal that /r/-liaison is rare in the speech of Educated Yoruba English.Distinct pronunciation of each word in connected speech, the nature of the rhythm of Nigerian English as a syllable-timed language and low level of awareness of /r/-liaison are the reasons provided for the rare occurrence of /r/-/liaison. 
In respect of its social correlate, /r/-liaison is used significantly by adult speakers of EYE more than the young speakers.Aside this,the findings also show that /r/-liaison is mostly used in-between grammatical items in lexicalised words as a result of long years of use.

Akinjobi (2004a) studied the extent to which vowels are reduced in noun or adjectives when they change to verbs. In Standard English, syllables that are assigned primary stress in words serving as nouns or adjectives become reduced and weakened in their verb forms. It is reported that Educated Yoruba Nigerian English (EYNE) speakers correctly stressed the noun and adjective forms of the words tested by $83 \%$ of the respondents. However, the subjects inappropriately produced the verb forms by $72.8 \%$ of the respondents, retaining the quality of the vowels in the syllables which are expected to change. Also, her findings reveal alternation of strong and weak syllables or vowels. That is, syllables or vowels which are expected to be longer are made shorter, while those which are to be shorter are rendered longer. Thus, the conclusion is drawn that, weak vowels and syllables are hardly realised by EYNE speakers in contrast to Standard English where they are frequently employed. Consequently, this underlies the distinct difference in the rhythmic patterns of the two languages.

Moreover, consonant deletion of $/ \mathrm{r} /$, and $/ \mathrm{n} /$ and $/ \mathrm{l} /$ alternation are identified to be the most frequent phonological processes in Yoruba (Okanlawon, 2016).But, epenthesis, substitution andelision arethe various modes by which consonant clustersare reduced in Educated Nigerian Spoken English (ENSE) as opined by Soneye and Faleye (2015).These three processes are categorised as segmental deviations (Malah and Rashid, 2015). The glottal fricative $\mathrm{h} / \mathrm{is}$ considered significant for the majority of NigE speakers (Awonusi, 2009). Its realisations are h-weakening, hrestoration, categorical h-dropping, variable h-dropping and h-epenthesis (insertion).H-weakening is the loss of $/ \mathrm{h} /$ in grammatical words in connected speech. The use of $/ \mathrm{h} /$ in words like heir, hour which are /h/-less in RP is hrestoration. Categorical h-dropping is the non-articulation of $/ \mathrm{h} /$ in $\mathrm{h}$-full words likehome. Variable h-dropping is the dropping of $/ \mathrm{h} /$ in some words. This process is not noticed only in NE but also in RP. H-epenthesis is the use of /h/in $\mathrm{h}-$ less words. In RP, h-epenthesis is found in the speech of uneducated speakers. However, it is used by both educated and uneducated speakers of Nigerian English, and this is reportedly common to the Yoruba (Awonusi, 2009) despite the presence of $/ \mathrm{h} /$ in the sound inventory of Yoruba. H-epenthesis arises as a hypercorrection by typically $\mathrm{h}$-dropping speakers. The awkward use of $/ \mathrm{h} /$ by the Yoruba is definitely connected to their cognitive functions and justification for this has hardly been made. This study, therefore, attempts to describe the cognitive process(es) that underlie the process of h-epenthesis by Educated Yoruba-English bilinguals.

\section{Optimality Theory (OT) and cognition}

OT is a linguistic model that came as a reaction to Generative Grammar (GG) which involves 'a kind of conceptual crisis at the center of phonological thought' (Prince and Smolensky, 2002). It is often called a connectionist theory of language, because it has its roots in neural network research. The field of phonology has always been comparing speakers' level of competence to their performance. It is undebatable that speakers know something about their languages, but focus in phonology is on what is exactly said by them. Often times, discrepancy is noticed between what is known and what is said. It can be said that, the major problem is not on the knowledge of what is to be said. Many a times, speakers possess adequate knowledge about the rules of their languages but their outputs do not justify this. The divergence between competence and performance calls for explanation. This is the major goal of any viable phonological theory. This has led to the development of many phonological theories such as OT.

The deviation between the level of competence of speakers and their performance relates to the difference between mental representations and surface representations. For every given word or sound, speakers have underlying mental representations but they may produce contrasting surface representation. The mental and surface representations are referred to as input and output representations. Thus, grammars are modelled, in OT, as systems that provide mappings from inputs into output. To select the most harmonic or optimal output form of an input, grammars regulate conflicts between constraints $(\mathrm{CON})$. These constraints are universal but each language specifies unique ranking for the universal constraints. Thus, this study examines the constraint ranked high in EYE in respect of h-epenthesis in h-less words.

\section{Methodology}

The data for the study were purposively elicited from thirty (30) educated Yoruba English bilinguals. They read a text which contained potentially h-inserting inputsinto a recording device. The tested items were grammatical words and content words starting with vowels. Survey design was employed.A structured questionnaire was given to them to fill. The consent of each respondent was sought after being informed of the purpose of data collection. Nobody was coerced; those who are indifferent were not forced to partake in the study. The data were listened to several times for transcription purpose. They wereperceptually and phonologically analysed. Phonological analysis was carried out by the use of Optimality Theory. 


\section{Perceptual analysis}

Table 1 below showsthe realisations of grammatical words with h-epenthesis.

\begin{tabular}{|c|c|c|c|}
\hline \multicolumn{3}{|c|}{ Inputs } & \multirow[t]{2}{*}{ Outputs } \\
\hline & $\begin{array}{l}\text { Strong } \\
\text { Form }\end{array}$ & $\begin{array}{l}\text { Weak } \\
\text { Form }\end{array}$ & \\
\hline I & $/ \mathrm{aI} /$ & $/ a /$ & $/ \mathrm{hav} /$ \\
\hline up & $/ \mathrm{Ap} /$ & & $/$ hop/ \\
\hline over & /auva/ & & /houva/ \\
\hline all & $/ 5: 1 /$ & & /ho:1// \\
\hline of & /ov/ & /ow/ & /hof/ \\
\hline us & $/ A \mathrm{~S} /$ & $/ a \mathrm{~s} /$ & /hos/ \\
\hline off & $/ \mathrm{of} /$ & & /hof/ \\
\hline are & $/ a /$ & $/ a, 21 /$ & $/ \mathrm{ha} /$ \\
\hline and & /and/ & $/ \mathrm{an} /$ & /han, hand \\
\hline as & $/ \mathbb{e} /$ & $/ a z /$ & /has/ \\
\hline on & $/ \mathrm{on} /$ & & /hon/ \\
\hline
\end{tabular}

Table 1

Conjunctions, determiners, pronouns, prepositions, auxiliary verbs and some adverbs, which are all referred to as grammatical or function words, are realised in their weak forms in sentences of Standard English.In the present study, pronoun $I$, preposition of, conjunction and, pronoun usand adverb as, which were all meant to be realised as their weak forms in the context of their usage, were not only realised as strong forms but also accompanied with $/ \mathrm{h} /$ at the initial position, resulting in entirely new words. Other tested grammatical words which do not have strong and weak forms are up, over, all, and off.They all have instances of h-epenthesis word-initially.

In some instances, the realised words are meaningless because they neither exist in English nor Yoruba.In some other instances, meaningful words are derived. For instance, I /aI, ə/changed to high /hal/ by h-epenthesis. Although the output is meaningful but the semantic properties of the sentence have been altered. In the same manner, up / $\mathrm{p} / \mathrm{was}$ realised as $/ \mathrm{hpp} /$. The meaning of the word also changed, thereby making the sentence ungrammatical and meaningless. With the insertion of $/ \mathrm{h} /$ before the peak of the first syllable of over, an entirely new meaningful word was not derived. Instead, the derived word /houva/ would be unfamiliar to the ears of native speakers who may want to interpret it to mean /hpvə/.The insertion of $/ \mathrm{h} /$ before the peak of the word all / $/ \mathrm{l} / \mathrm{changed}$ the word to hall /hs:l/. This also derives a meaningful word. The inserted $/ \mathrm{h} /$ serves as onset of the syllable of the derived word.

Moreover, the insertion of $/ \mathrm{h} /$ before the peaks of of and offresults in meaningless words. However, the insertion of $/ \mathrm{h} /$ before the peak of $u s$ changed the word to a new word. The derived word is the same as horse because distinction between long and short vowel is notmade in Yoruba.With the insertion of $/ \mathrm{h} /$ in the word are, the derived word becomes meaningless. The word and had two realisations by the subjects. It was realised as han and hand. Perhaps the subjects who pronounced it as hanattempted to pronounce it in its weak form but could not avoid h-epenthesis. The reason for this is not unconnected with the mental indication of h-epenthesis in Educated Yoruba-English bilinguals, and this is the main thrust of this study. Unlike the first output, the second realisation had meaning but altered the meaning of the sentence, making it meaningless too. Insertion of $/ \mathrm{h} / \mathrm{in}$ as results in a new word has. So also, the derived word for on coincides with the word horn because distinction in vowel quality is hardly realised by Educated YorubaEnglish bilinguals. 
Table 2 below shows the realisations of content words with h-epenthesis

\begin{tabular}{|c|c|c|}
\hline \multicolumn{2}{|l|}{ Inputs } & Outputs \\
\hline asked & /a:skt/ & /haskd/ \\
\hline add & $/ x d /$ & /had/ \\
\hline eves & /aIs/ & /hais/ \\
\hline oath & $/ \partial v \theta /$ & /hot/ \\
\hline ofifice & /ofis/ & /hofis/ \\
\hline ever & /eva/ & /heva/ \\
\hline east & /i:st/ & /hi:st/ \\
\hline eggs & $/ e g z /$ & /hegs/ \\
\hline eat & $/ \mathrm{i}: \mathrm{t} /$ & /hi:t/ \\
\hline early & $/ 3: 1 i /$ & /hs:li// \\
\hline allegiance & /alidzənts/' & /halidjians/ \\
\hline almighty & /o:lmarti/ & /ho:1maiti/ \\
\hline however & /haueva/ & /haoheva/ \\
\hline
\end{tabular}

Table 2

$\mathrm{H}$-epenthesisaffects all forms of syllables, ranging from monosyllabic word to polysyllabic words. Since it has positional restriction, $/ \mathrm{h} /$ is inserted into the onset positions of all the words. It does not only change the structures of the words but also the meaning. Most of the derived words are meaningless, such as hasked, heyes, hoffice, hever, heast, hegs, hearly, hallegiance, halmighty and howhever.

\section{Phonological analysis}

The perceptual analysis presented above supports the hypothesis that $/ \mathrm{h} /$ is frequently inserted by Yoruba-English speakers before vowels in h-less words. This reveals a form of divergence between their level of competence and performance. In respect of competence, all Educated Yoruba-English speakers know the correct spelling of each of the tested words. Hardly will any of them start the words with letter ' $h$ ' while writing. However, the unconsciously insert it while speaking. The correct spelling of the words is the input, while the unconscious realisationof the words with $/ \mathrm{h} /$ is the output. This, therefore, suggests that between the levels of input (mental representation) and output (surface representation), there is an intervening process.

That process is the insertion of $/ \mathrm{h} /$ not in any other syllable or word position but initial position. This occurs only in words initiated by peak. The inserted $/ \mathrm{h} /$ serves as the onsets of the derived words. Since $/ \mathrm{h} /$ is not present in the mental representation (input or underlying form), the output which has h-epenthesis is not faithful to the input. Therefore, a Markedness constraint is ranked high in EYE speakers. A hasty conclusion may be made that the constraint ONSET, which stipulates that syllables begin with a consonant, is responsible for h-epenthesis. This constraint has some pivotalrestriction in respect of the focus of this present study because it only specifies the position of epenthesis and not the nature of the segment epenthesised. Any word with other consonants serving as onsets would be spared by the constraint. This is illustrated with tableau 1 below.

\section{${ }^{1}$ RANKING: ONSET>>DEP}

Tableau 1 ONSET restriction in h-epenthesis

\begin{tabular}{|c|c|c|}
\hline$/ \mathrm{r} /$ & ONSET & DEP \\
\hline A. $/ \mathrm{ra} /$ & $* !$ & \\
\hline B. $\sigma / \mathrm{hr} /$ & & $*$ \\
\hline C. $\sigma / \mathrm{tr} /$ & & $*$ \\
\hline
\end{tabular}

${ }^{1}$ ONSET: Syllable begins with a consonant

DEP: Every segment of the output has a correspondent in the input (no epenthesis). 
In tableau1 above, two candidates emerge as winners because the highest-ranked constraint, ONSET, is not strong enough to determine the optimal output. Candidate A, which is faithful to the input, violates ONSET. This qualifies it from the competition irrespective of its satisfaction of DEP, which ranks low in the competition. Candidates B and C have onset; they do not violate ONSET. The insertion of glottal fricative $/ \mathrm{h} /$ and voiceless alveolar plosive $/ \mathrm{t} / \mathrm{makes}$ them satisfy ONSET but violates DEP. Since the violation is not fatal, they become optimal. None of them can be ruled out because they both have onset, which is required by the highest-ranked constraint.

Thus, it becomes obvious that ONSET is not responsible for /h/-epenthesis in EYE speakers.Therefore, a new constraint, which specifies not only the position but also the exact segment epenthesised, is proposed.ONSET[h]requires that a syllable begins with specified consonant $-[\mathrm{h}]$. This constraint is ranked high in the grammar of EYE speakers when they encounter peak-initiated words. This explains the reason while only /h/, and not any other consonants, is inserted by the subjects of this study in the tested words.For instance, given the input out, the probability of having it realised by EYE speakers as hout is higher than tout, even though houtexists neither in the lexicons of English nor Yoruba. Tableau 3 below shows the competition between the two alternatives.

Tableau 2 Emergence of /havt/

${ }^{2}$ RANKING: ONSET [h] $>>$ DEP

\begin{tabular}{|l|c|c|}
\hline$/$ aut/ & ONSET $[\mathrm{h}]$ & DEP \\
\hline A. $/$ taut/ & $* !$ & $*$ \\
\hline B. $/$ haut/ & & $*$ \\
\hline C. $/$ aut/ & $* !$ & \\
\hline
\end{tabular}

In tableau 2, Candidate Ais knocked out of the competition because it does not have glottal fricative $/ \mathrm{h} / \mathrm{as}$ its onset. It fatally violates ONSET [h].Although it equally violates DEP but this violation is less serious. Candidate $\mathrm{C}$ also violates ONSET $[\mathrm{h}]$ and is knocked out from competing any further. Candidate B satisfies ONSET $[\mathrm{h}]$ in order to violate DEP. In the present study, the violation of DEP is less serious. Thus, candidate B becomes the optimal output.For the analysis of the tested items, two grammatical words and two content words are selected and represented on tableaux below.

Tableau 3 Emergence of /hai/

RANKING: ONSET $[\mathrm{h}]>>$ DEP

\begin{tabular}{|c|c|c|}
\hline$/ \mathrm{o}: 1 /$ & ONSET $[\mathrm{h}]$ & DEP \\
\hline A. $/ \mathrm{o}: 1 /$ & $* !$ & \\
\hline B. $\sigma / \mathrm{h} \%: 1 /$ & & $*$ \\
\hline
\end{tabular}

Tableau 4 Emergence of $/ \mathrm{h}:: 1 \wedge$

RANKING: ONSET [h] >>DEP

\begin{tabular}{|c|c|c|}
\hline$/$ i:st/ & ONSET $[\mathrm{h}]$ & DEP \\
\hline A. $/ \mathrm{i}: \mathrm{st} /$ & $* !$ & \\
\hline B. $\cdot$ /hi:st/ & & $*$ \\
\hline
\end{tabular}

Tableau 5 Emergence of /hi:st/ RANKING: ONSET [h] >>DEP

${ }^{2}$ ONSET: Syllable begins with the specified consonant $-\mathrm{h}$.

DEP: Every segment of the output has a correspondent in the input (no epenthesis).

136 


\begin{tabular}{|c|c|c|}
\hline$/$ /:Imaiti/ & ONSET $[\mathrm{h}]$ & DEP \\
\hline A. $/$ :Imaiti/ & $* !$ & \\
\hline B. $/$ ho:Imaiti/ & & $*$ \\
\hline
\end{tabular}

Tableau 6 Emergence of/ho:lmaiti/

RANKING: ONSET [h] >>DEP

In all the tableaux, candidates $A$ are faithful to the inputs but candidates $B$ are not because of $/ \mathrm{h} /$ epenthesis which is absent from the underlying forms. Because of their faithfulness to the inputs, candidates A violate the highest-ranked constraint, ONSET $[\mathrm{h}]$. They are all disqualified from the competition, even though they satisfy the second constraint because they do not have record of segment epenthesis. This is because the violation of a highly-ranked constraint can never be compensated for by the satisfaction of a low-ranked constraint. However, all candidates B emerge as winners because they all satisfy the highest-ranked constraintand violate DEP, which is low-ranked in the analysis.

\section{Conclusion}

The objective of this study was to detect the cognitive motivation of h-epenthesis in Educated Yoruba English speakers.It was revealed in this study that theinserted segment before peak-initiated words in the speech of the subjects is $/ \mathrm{h} /$, regardless of the level of their educational attainment. That is, lack of (quality) education is really not the reason for this type of h-realisation by Yoruba English speakers. It appears to be peculiar to a majority of Yoruba English bilinguals, the educated and the uneducated inclusive. In this study, h-epenthesis occurred both in grammatical and content wordswith all kinds of vowels without any recourse to their quantity or quality. These resulted into the generation of many meaningless words and some meaningful words which distorted the intended semantic properties of sentences.

Through the versatility of Optimality Theory, an insight is provided into the nature of the grammar of the Yoruba English bilinguals; a constraint which is hardly employed by native speakers is not only employed but also highly ranked in the grammar of Yoruba English bilinguals. It is argued in this study that the markedness constraint, ONSET, which accounts cross-linguistically for different types of consonant epenthesis, is not responsible for h-epenthesis. This is owing to its inability to specify the precise segment that is inserted. Therefore, a new constraint, ONSET [h], is proposed to be responsible for the process of h-epenthesis. When this constraint is ranked high, DEP is demoted. Thus, an output with $/ \mathrm{h} /$ is realised. For EYE speakers who hardly insert $/ \mathrm{h} /$, ONSET $[\mathrm{h}]$ has only been demoted and not deleted; they can, either unconsciously or when in a very informal and relaxed mood, still realise outputs with hepenthesis. Since the constraint ONSET [h], which is not reckoned with in the grammar of native speakers, is highly ranked in the grammar of Yoruba English speakers, a marked area of divergence is established. This may contribute to communication failure between native speakers and Educated Yoruba English speakers.

\section{References}

Adesanoye, F. A. 1973. A study of varieties of written English in Nigeria. PhD. Thesis. Dept. of Linguistics. University of Ibadan.

Akindele, F. and Adegbite, W. 1999. The sociology and politics of English in Nigeria: an introduction. Ife: OAU Press. Akinjobi, A. A.2004. A phonological study of the influence of word stress shift on educated Yoruba English vowels and syllables. Forms and functions of English and indigenous languages in Nigeria: a festschrift in honour of Ayo Banjo. K. Owolabi and A. Dasylva.Eds. Ibadan: Group Publishers. 558-576. 2005. Vowel reduction in the unstressed syllables of educated Yoruba English words. Centrepoint 11.1: 185201. 2006. Vowel reduction and suffixation in Nigeria: an analysis of the educated usage of speakers of Yoruba English. English Today 22.1: 10-17.

2007. An instrumental analysis of some English grammatical words as pronounced in the spontaneous speeches of a BBC (RP) speaker and an educated Yoruba English speaker. Ibadan Journal of English Studies 4: 38-47.

---------. 2009a. English syllabic consonants and quantity factor in educated Yoruba Nigerian English. African Research Review 3.2: 45-55. 
2009b. A study of the use of the weak forms of English grammatical words by educated Yoruba (Nigeria) English speakers.African Research Review 3.3: 81 - 94.

Akinkurolere, S. O. and Adewumi, S. I. 2013. Translation and its linguistic implications for Yoruba/English bilinguals. Research on Humanities and Social Sciences 3.15: 2013.

Atoye, R. O. 1980. Sociolinguistics of phonological interference in Yoruba-English. PhD. Thesis. Dept. of English. University of Sheffield. iii +121 .

Awonusi, V. O. 2004. RP and the sociolinguistic realities of non-native English accents. Forms and functions of English and indigenous languages in Nigeria: a festschrift in honour of Ayo Banjo. K. Owolabi and A. Dasylva.Eds. Ibadan: Group Publishers.

-----------. 2009. Some characteristics of Nigerian English phonology.Nigerian English: influences and characteristics. 2nd ed. A.B.K. Dadzie and S. Awonusi. Eds. Lagos: Sam Iroanusi Publications. 203-225.

Bamgbose, A. 1995. English in the Nigerian environment.New Englishes: a West African perspective.A. Bamgbose, A. Banjo and A. Thomas. Eds. Ibadan: Mosuro.

Banjo, A.1971. Towards a definition of Standard Nigerian Spoken English. Actes du 8 congrus de la societe linguistique de l'afrique occidentale Abidjan: University of Abidjan 165-175.

Ekpe, M. B. 2010. The English language in Nigeria. Lagos:National Open University.

Igboanusi, H. 2006. A comparative study of the phonological features of Igbo English and Yoruba English speakers of Nigeria. English Studies 87.4: 490 - 497.

Jowitt, D. 2014. Nigerian English lexis: neologisms and archaisms.English Language Clinic Lecture Series 1- 5and correction of common errors. A publication of English Language Clinic Programmes of University of Ibadan

Malah, Z. and Rashid, S. M. 2015. Contrastive analysis of the segmental phonemes of English and Hausa languages. International Journal of Languages, Literature and Linguistics 1.2: 106-112.

Odumuh, A. 1987. Nigerian English (NigE). Zaria: Ahmadu Bello University Press Ltd.

Ogundepo, A. O. 2015. Contrastive study of English and Yoruba morphological systems: implications for Nigerian English teachers and learners of English. International Journal of English Language and Linguistics Research 3.4: $1-8$.

Okanlawon, J. 2016. An analysis of the Yoruba language with English. Retrieved Aug. 8, 2017, from http://www.northeastern.edu/cos/linguistics/wp-content/uploads/sites.

Oladipupo, R. O. 2014. Social and linguistic correlates of r-liaison in educated Yoruba English. Ife Studies in English Language 11.1: 113.

--------. and Akinjobi, A. A. 2015. A sociophonetic study of young Nigerian English speakers.Ghana Journal of Linguistics 4.2: 92-107.

Olaniyi, O. K. 2011. Articulation as a means of identifying Educated Nigerian speakers of English: a phonosociolinguistic study. PhD. Thesis. Dept. of English. University of Ilorin.

Olaoye, A. A. 1989. The morphosyntax of English-Yoruba code-mixing: a bilingual education perspective. Language Research 25.2: 295-308.

Prince, A. and Smolensky, P. 2002. Optimality Theory: constraint interaction in generative grammar. Retrieved Sept. 10, 2014, from http://roa.rutgers.edu/files/562-1102/562-1102-PRINCE-0-0.PDF.

Robbin, A. A. 2010. Language switch and cognitive dissonance: the example of Yoruba-English bilinguals. Ife Studies in English Language8.1: 34-49.

2011. Empirical analysis of the contributions of cognitive dissonance to Yoruba-English bilinguals language switch practice. African Journal of Arts and Cultural Studies4.1. Retrieved Aug. 10, 2017, from http://www.irdionline.com/africanjournals/article/EMPIRICAL\%20ANALYSIS.pdf.

Soneye, T. and Faleye, J. O. 2015. Syllable phonotactics in educated Nigerian spoken English. Konin Language Studies 3.3: 255-269.

Tiffen, B. W. 1974. The intelligibility of Nigerian English. PhD. Thesis. Department of Phonetics. University of London.

Ufomata, T. 2004. Tone and stress in contact: the example of English loanwords in Yoruba. Forms and functions of English and indigenous languages in Nigeria: a festschrift in honour of Ayo Banjo. K. Owolabi and A. Dasylva. Eds. Ibadan: Group Publishers. 577-592.

Utulu, D. C. 2014. A phonetic analysis of Educated Urhobo English segmentals. PhD. Thesis. Dept. of English. University of Ibadan. 